\title{
Pedagogues about the Principle of Consciousness and Activity in Education
}

\author{
Khazangul Ramazanova ${ }^{1}$ \\ ${ }^{1}$ Ganja State University, Ganja, Azerbaijan \\ Correspondence: Khazangul Ramazanova, Ganja State University, Ganja, Azerbaijan. E-mail: \\ khazangul.ramazanova@mail.ru
}

Received: June 19, 2013 Accepted: May 11, 2014 Online Published: May 30, 2014

doi:10.5539/ass.v10n11p277 URL: http://dx.doi.org/10.5539/ass.v10n11p277

\begin{abstract}
The article is devoted to the principle of conciousness and activity in the education system of some CIS countries, as well Azerbaijan. It is shown that the education methods and principles play the main role in regard of optimization of teaching process, promotion of education quality and effective possession of the knowledge. The article also clarified the place of the principle of conciousness and activity among different principles of education, and useful applying ways of this principle. At the same time, the thoughts and ideas of various pedagogues and scientists in this field were compared.
\end{abstract}

Keywords: principle of consciousness and activity, education system, cognitive activity, creative independence, motivation, optimization of education process.

\section{Introduction}

The long history of the mankind, through several centuries, has established that the educational system and its content have been established to serve the human future. Presently, the education system has a sensible effect on the socioeconomic development of the society. Therefore, when we consider the duties of the mankind in the $11^{\text {th }}$ century, the determination of the education development directions appears to be the first duty. The deep integration process, which has found its way to the social life, has also opened its way into the education. The integration will eventually lead us into the convergence of the educational systems in different countries and the formation of a unique educational center.

Nowadays, everybody is interested in the perspective of the ongoing educational development in our country. Everybody, from the President of the Republic of Azerbaijan to the common teachers, is concerned about its future. One of our immediate duties is the promotion of quality level of the education.

Recently, the analysts have mainly focused on the quality of education when compared with other aspects of the field. This has its own causes. The education quality means the prevailing values in the educational institutions and the protection and safeguarding the education management. Among them we can point out really targeted knowledge search and development of the knowledge without seeking any consideration. A lot of measures are undertaken aiming the promotion of quality of the education: a commission has been formed in Europe to evaluate the education quality; also, several seminars and conferences are organized in our country to address this field of concern. Taking the global experiences as a guiding line and by utilization of the principles, which have been applied in the field of education for a while and of those are applied currently, the content of education is improved, special attention is devoted to the quality of education management, the teaching process is optimized and preparation of teaching staff is promoted.

Despite the foregoing, we have to acknowledge this fact the concept of the education quality has not been bee formulated sufficiently: the approaches are determined, the quality indicators are identified, its directions are developed and the criteria are clarified. Therefore, the innovation in the education sector and removal of some deficiencies seem to be an essential. Some of the educational institutions are facing with hardship to provide the education to their graduates in the level outlined in the governmental standards prevailing in the field of education. Then, the development process of the schools shall be investigated accurately, and the scientific principles of quality concept in the education, its realization, foreseeing the target, the outcome and its determination shall be determined accurately and correctly. 
In other words, the quality of education means that the quality of each subject and topic, every taught knowledge and materials shall form the core of every educational activity, the classrooms shall be equipped with the modern equipment and become ready for teaching, the teachers shall demonstrate their abilities and capabilities from the points of view of theoretical and methodical, the provisions shall be done for formation of cognitive activity of students, their independency shall be secured, the initiative actions of the students shall be defended, at the time of evaluation of the knowledge and life experience of the learners, the conscious learning shall be taken into account instead of mechanical cramming and the activity of the students shall be used as basic factor in teaching the subjects. The quality management forms the essence of the education system. Indeed, the quality of the education is object of the educational management.

The qualitative aspects of the education have always been among the topics in this sector. Just like every other sector, the education sector also requires quality development. In recent years, the quality has been become one of the subject that are more frequently discussed and researched.

As we know, the human development has three indicators: (1) the education level, (2) the per capita income, and (3) the average age of the people.

Among them the education index has a paramount importance. In recent day, the dramatic changes are occurring in the schools throughout the Republic of Azerbaijan (construction of schools, repairing schools, provision of equipment and computer, etc.). For some reasons, the teaching process and teacher - student - parents relationship is not in the required high level. Some of the teachers do not possess the new knowledge.

The qualitative education is a social requirement of the government, the students including the primary school students and higher education students. The promotion of the quality of the education is the main objective of the reforms taken place in the education sector.

We can evaluate the education system as a qualitative system if not only the students but also the teachers as one of the main players of education process to possess a known achievements. Students including the primary school students are our main target and not only we have to provide them knowledge but rather we have to teach them the work practices and formation of an appropriate lifestyle and the capability to cope with the changing environment.

\section{Core Requirement of the Implementation of Principle of Consciousness and Activity in the CIS Countries}

The education methods and principles play the main role in regard of optimization of teaching process, promotion of education quality and effective possession of the knowledge. From this point of view, the consciousness and activeness have a unique importance. The classic and also the contemporary teachers have provided valuable thoughts about those principles, their nature, contents, applied features and capabilities and also their interaction with other principles of the education.

Today, just like every other time, the students are expected to acquire the independency in many techniques and skills, openly reflection their thoughts, their innovation, and consciously learn the matters contained educational materials. Our time requires the cognitive activity and creative independence of the students including primary school students and higher education students as the stockholders of the education system with equal rights. It is true that if the students consciously learn the content of the learning materials, not only they will react actively but also they try to apply their acquired knowledge in the practice. In practice comprehension and activity processes are closely related. Therefore, it is impossible to tear them from each other.

The following issues shall be taken into account at the time of implementation of principles of consciousness and activeness:

1) Teacher should form motivation of active informative activity of school pupils at lessons.

2) Teacher should achieve, that schoolboys meaningly would carry out operations and actions, guide on the purpose, problems, content of a program material and conditions of its fulfillment, direct strong-willed and physical efforts for decision of problems, show activity and initiative, could render mutual aid to each other and so on at lessons

We investigated the materials used for pedagogic teaching purposes in other countries, especially in CIS countries, to learn about the situation of education principles, more especially the consciousness and activeness. We found up that the consciousness and activeness among other principles are highly assessed in P.I. Pidkasistiy and V.V. Voronov education systems. They write: "Traditional didactics, as is known, underestimates activity of 
pupils. Pedocentrist didactics overestimates it. Modern system of teaching is guided by activity of pupils at a guiding role of teacher. Activity and deliberateness in teaching may be achieved if:

1) to rely on interests of pupils and at the same time form motives of teaching among which educational interests, professional propensities are at the first place;

2) to involve pupils to decision of problem situations, problem education, process of search and scientific and practical problems solving;

3) to use such methods of teaching as didactic games, discussions;

4) to stimulate collective forms of work, interaction of pupils in learning.

Realization of the considered principle promotes not only formation of knowledge and development of children, but also their social growth, education" (Podkasistiy, 2001)

The importance of the specified principle in L. V. Zankov's researches is also particularly mentioned. According to its right conclusion "deliberate learning strengthens developing influence of educational process on pupils. Conscious learning of knowledge prevents formalism and, at the same time, promotes their transformation into deep and steady belief of school learners. Activity and deliberateness of learners at studies should develop in close interrelation".

Professors J. K. Babansky and V. A. Slastenin directed attention to realization of principle of deliberateness and activity in practice. Concerning it they write the following: "Teaching experience of many teachers confirms that a variety of teaching methods promotes development of various types of storing, thinking and interests of school pupils. It is necessary to apply conversations more widely, create problem situations, put pupils before necessity to prove, give reason, convince, criticize different points of view in the course of teaching, expand forms and methods of independent work of school pupils at lessons, learn them rational techniques of organization of educational activity, ability to make the plan of answer, the plan of essay, etc. (Babanskiy, 1988)

According to the Professor T. A. Ilyina "principle of deliberateness and activity is shown also at the closing stage of knowledge process, that is, at the stage of application of knowledge in practice". Speaking about principle of deliberateness and activity, T. A. Ilyina gives the following examples: "Principle of deliberateness and activity consists in purposeful active perception of the studied phenomena, their judgment, creative processing and application. First of all, it is caused by two-way character of the teaching process in which learning is possible only when pupil is active" (Ilyina, 1984)

Further the professor specifies: "Principle of deliberateness and activity reflects active position of a learner in educational knowledge and underlines value of a stage of deliberateness - understanding - comprehension. This active deliberate position is deepen at purpose comprehension, aspiration to show and open the creative abilities" more full. (Ilyina, 1984) According to T. A. Ilyina: "deepening of the conscious approach to lessons and stimulation of intellectual activity of pupils is promoted by statement of informative problems, creation of a problem situation and a number of other techniques and methods stimulating activity of pupils". (Ilyina, 1984) There are also I. P. Podlasiy's valuable opinions in connection with deliberateness and activity principle. He states: "Practically the principle of deliberateness and activity of teaching is carried out by observance of some important rules of teaching. I. P. Podlasiy draws attention basically on 23 rules. Let's pay attention: "Clear understanding of the purposes and problems of forthcoming work is a necessary condition of deliberate teaching, that is you need to show them to pupils, explain importance and value, open prospects:

1) Learn pupil so that he could understand why and how it is necessary to do and once did not mechanically carry out educational actions, not having realised them preliminary and deeply.

2) Teaching uses all types and forms of informative activity, unite analysis with synthesis, induction with deduction, comparison with opposition, begin with an induction more often.

3) Provide understanding of sense of each word, the offer, concept by learners; open them relying on knowledge and experience of pupils use figurative comparisons. Do not enter concepts on which detailed disclosing you do not expect.

4) Use force of intereducation of pupils. Provide appropriate conditions for development of collective forms of search of right answer. What is spoken by companion is perceived better and easier than an explanation by teacher, so why you should not explain that that may be explained by your best pupils in class... ". (Podlasiy, 2000)

According to I. F. Kharlamov, the consciousness and activeness in the education system is regarded as a natural indication. He also regards such natural aspect as an active teaching-cognitive activity process having its roots in 
the essence of the education. Let's pay attention: "In realization of this regularity pupils' stimulation of requirement for mastering by knowledge, use various receptions of activation of their informative activity (statement of questions, prompting to definition of conclusions on the basis of analysis of actual material etc.), expansion of independent work on understanding of and mastering of the material studied, carrying out of supervisions, organization of practical works and so on, skilful development of such cogitative actions, as analysis, generalization, conclusion, encouragement of creativity, ingenuity etc. have significant value". (Kharlamov, 2004) ("In the implementation of this law are essential: excitation students need to master knowledge, the use of various techniques to enhance their cognitive activity (asking questions, the impulse to draw conclusions based on the analysis of factual material etc., the expansion of independent work on understanding and mastering studied material, conducting surveillance, practical work, etc.: the skilful development of such mental operations as analysis, synthesis, inference, encouraging creativity, ingenuity, etc. (Kharlamov, 2004).

\section{Azerbaijani Pedagogues about Principle of Consciousness and Activity in Education}

The Azerbaijani teachers also highly valuate the consciousness and activeness in the education system and have to do so. According to them, the consciousness helps the formation of activeness both in teaching and education of the growing generation.

The consciousness and activeness principle has a long history. According to Professor M. A. Muradkhanov, these principles have been established to work against the dogmatic teaching system. Professor M. A. Muradkhanov adds: "the concept of dogmatic teaching means learning the subjects without any proving and reasoning, and cramming the subject without knowing anything bout its real meaning. Such a teaching system suits for the middle age. In the middle ages, the students were forced to learn the subjects without appropriate proof and reasoning just because it's taught by a holy teacher having its power source in the Bible. This would lead the students to passiveness, cramming and destroys their thinking capabilities." (Muradkhanov, Hashimov, Valikhanli \& Afandiyev, 1964)

One of aspects of the education, which has extremer importance towards formation of true relationship of primary school students with their surrounding world and also formation of an appropriate believe and faith. It is a reality that if the knowledge is learned consciously, will eventually turned into believe and faith in the human. But the education system provides only knowledge to the students including the students of the primary school course and they learn about believe and faith personally, i.e. conscious learning. The consciousness of the students in regard of learning the materials by the students is highly dependent on the teacher's activities. Such a teacher always concentrates on the students' attention, stimulates the students to deal with the problem situations, but the questions lower than the development level, will not result in activation of the students' attention.

Saying the principle of consciousness and activity will consist of the following aspects:

1) The formation of consciousness attitude in the students towards the education;

2) Formation of activity in learning the knowledge which in turn results in thinking about the objects, things and events that the students learns about them;

3) Formation of the capability to apply the learned theoretical knowledge in practice;

4) The students learn about the aim of their education and will effort to realize it. This in turn will result in formation of consciousness and activity in the students;

5) Learning about the ways and means for attainment to the aim;

6) Deep understanding about the scientific facts and observation of regulations, reflection of the teaching materials in the students' cognitive activities;

7) Active learning the knowledge and their application in a creative way.

In the textbook written by Professor A. N. Abbasov for the technical high school course, he has paid appropriate attention to principles of consciousness and activity. According to the professor, this principle together with the presence of the student in the learning classroom play relatively decisive role in the education process. The textbook outlines: "the conscious attitude to the professions results in formation of cognitive activity, laying down the cognitive duties, formation of cases of problem resolving situation, and stimulation of activity in the students and provides for application a set of knowledge and methodologies. The conscious learning of different materials will leas the student to comparison of the new knowledge with the existing knowledge and ideas, their classification, and formation of intra-science and inter-science relationships. In addition to the learned essential knowledge, the skills and practice should also been dealt consciously." (Abbasov, 2010) 
The "pedagogy" deals with the principles like textbooks and teaching materials, also establishment relationships between the pedagogy \& methodic literature with the life; systematic and consistency nature; the relationship between the scientific and visual aspects of teaching with the practice; cooperation; competency, the consideration of the personal characteristics and possibility in the teaching; the individual approaches; taking into consideration the individual understanding and characteristics of the students etc. and provides the essential suggestions towards their effective application.

In addition to the traditional principles pointed out by Professor N. M. Kazimov the educational aspects of the learning; the educational aspect of the learning; the development aspect of the learning; provision of suitable conditions for the education and its consistency; the principles of truth and feedback of the knowledge; the principle of role of the visualization in the knowledge; and the use of different principles (Kazimov, 2002); H. H. Ahmadov, Ph. D. in the field of pedagogy, has also outlined some other principles like humanization; environment friendly; integrity; democratized; civilized; professionalism; advisability; and polytechnic natures to those principles (Ahmadov, 2006)

According to Professor N. M. Kazimov, the consciousness and activity of the students during the learning process has also its roots in an idea which indicates that in such approach the student is not regarded as object of learning process rather the students are the subject of the process and form another part of the whole of the process. Under supervision and leadership of the teacher, the student learns to think, to express his / her thought, to observe, to conclude, to make effort to remove the mistakes, to draw up the plan, to active on plan based, to collect the materials, to group the collected materials, to experience them, to analyze the obtained results, etc.

\section{Conclusion}

We see that all the foregoing are true and reality. In addition, some teachers of the country like A. O. Mehrabov, Y. Sh. Karimov, Y. R. Talibov, F. B. Sadiqov, H. A. Alizada, L. N. Qasimova, A. M. Hasanov, R. Sh. Mustafayeva, M. Ismikhanov and others in their works written in a pedagogic way, books and booklets, papers, and also the textbooks and teaching materials have paid wide attention to the consciousness and activity in the teaching process.

According to the foregoing, we can conclude that the consciousness learning of the knowledge by the students is dependent on efforts, attention and carefulness of the teachers, families and parents. Such a process will prevent from cramming, increases the interest of the students including primary school students to the learning and make them more active. Principle of consciousness and activity of junior high school students approves their subjectivity in the process of learning. The rationale is that the activity of pupils is social in nature and subject. It is an integrated indicator of its focus and active essence. The investigations, observations, and surveys show that using in its proper place and efficiently the principle of consciousness and activity in the course allows younger pupils to learn teaching materials at a high level, to gain successfully life skills, and creates conditions for improving the quality of teaching.

\section{References}

Abbasov, A. N. (2010). Pedagogy: Textbook for secondary specialized schools. Baku: Mutarjim (translation).

Ahmadov, H. H. (2006). Pedagogy: Textbook for secondary specialized school. Baku: AIU

Babanskiy, Y. K. (Ed.). (1988). Pedagogy: Tutorial for students of pedagogical institutes. Moscow: Prosvesheniye.

Ilyina, T. A. (1984). Pedagogy. Course of lectures. Tutorial for students of pedagogical institutes. Moscow: Prosvesheniye.

Kazimov, N. M. (2002). School Pedagogy: textbook for bachelor degree of higher schools. Baku: Chashioglu.

Kharlamov, I. F. (2004). Pedagogy: Brief course. Minsk: Highest school.

Muradkhanov, M., Hashimov, A., Valikhanli, I., \& Afandiyev, T. (1964). Pedagogy: Textbook for higher schools. Baku: Azerbaijan State Education- Pedagogical literature publishing house.

Podkasistiy, P. I. (Ed.). (2001). Pedagogy: tutorial for students of pedagogical institutes of higher education and pedagogical colleges. Moscow: Pedagogical society of Russia.

Podlasiy, I. P. (2000). Pedagogy of primary school: tutorial for students of pedagogical colleges. Moscow, Humanitarian publishing centre: VLADOS. 


\section{Copyrights}

Copyright for this article is retained by the author(s), with first publication rights granted to the journal.

This is an open-access article distributed under the terms and conditions of the Creative Commons Attribution license (http://creativecommons.org/licenses/by/3.0/). 